\section{SCIENCE, TECHNOLOGY AND THE SUPERNATURAL IN CONTEMPORARY THAI NOVELS}

\section{Pornvipa Watarachanakool $^{1}$}

\begin{abstract}
As science and technology gain a high reputation and perform an increasingly dominant role in the present globalized era, old knowledge and wisdom, especially local forms, are fast disappearing. Will this trend necessarily bring about a brighter future for the whole world? Are science and technology trustworthy enough and safe enough for human beings to rely on without the other, dated, form of knowledge? These questions comprise the main interest of this paper, which endeavors to search for ideas, practices, and, also, expectations about the stated issues from Thai contemporary novels, in order to examine whether or not there is such a trend in Thai society, and what is the explanation. From literary and cultural anthropological perspectives, the findings seem to reflect that the Thai urban population are well aware of the increasing significance of science and technology and welcome them with enthusiasm. However, for the majority of the rural citizens, the information found presents a rather active role of local cultures and religion, which are closely related to beliefs in the supernatural. This paper is attempts to present some insight into this important issue.
\end{abstract}

${ }^{1} \mathrm{Ph} . \mathrm{D}$. Candidate (Literature and Comparative Literature) Chulalongkorn University, Bangkok, Thailand

\section{Introduction}

While science and technology have been rapidly progressing, many people, especially those who are not in the position to reap the benefits directly, are increasingly nervous about the advanced materialistic world created by them. Are science and technology able to completely control everything? Will science and technology truly bring about human luxuries? And, do any risks lurk behind these seemingly smart and smooth paths laid down by science and technology?

From the literary perspective, contemporary Thai novels reflect both admiration for and concern with the advances of science and technology in the present day. Twenty Thai novels, whose main contents comprise stories of science, technology, and the supernatural, published between 1987 and 2003 have been studied for this current research project, which is part of the Research Program on Science and Technology in Thai Society and Culture, funded by the National Research Council of Thailand. This study investigates some salient ideas regarding these three areas in Thai society, in which the non-scientific appears to be a dominant force, despite efforts to educate and integrate science and technology into its fabric.

The focus period of the study begins in 1987, which is the first year that the Thai government implemented the Sixth Economic and Social Development Plan focusing on applying science and technology to development processes. The plan affected the whole of Thai society and later inaugurated the period of the bubble economy. Contemporary novels using several styles, social-realism, fantasy, and science fiction, have been chosen for intensive study in order to observe 
reflections or presentations of the ideas under examination in Thai society.

Three questions to be answered in this paper include: What are the real causes obstructing the encouragement of scientific thought in Thai society? Can Thai people ignore ideas about the supernatural and accept scientific rules? Also, does the supernatural have any special function in Thai life, thus, is it inherited, and does it remain unchanged in Thai society?

\section{Reflections of science, technology and the supernatural in contemporary Thai novels}

Through close reading and analysis of the novels sampled, it is found that all these texts encourage a scientific way of thinking. Many authors emphasize that educated people, university graduates in particular, should not believe in any kind of supernatural power or superstition. They obviously criticize such power as irrational, old-fashioned, or nonsensical. However, some novels present the plot of confrontation between the protagonists' faith in rationality and empirical form of the supernatural. It is clear that many authors still believe that the supernatural really exists, while, at the same time, they believe in scientific thinking.

This contradiction is quite common in Thai society, and it is quite clearly reflected in novels studied. This could possibly be explained by two dominant factors: culture and Buddhism in Thai society. Let us consider culture first. Most Thais, especially in rural areas, are from extended families. The members are closely related, and elders are highly respected. Culture or tradition, and religion as well, are directly transmitted from generation to generation by means of the young absorbing the practices and beliefs from their parents and from the community around them. Supernatural beliefs and practices have deep roots in local Thai cultures, especially in remote areas among uneducated people. Socialization is much more influential to the people than formal education. Therefore, many kinds of supernatural power and practices are inevitable among rural people whose traditions and culture still play important roles.

An obvious example of this point is shown in a novel entitled The Extraterrestrial (Nantana, 1987). The author intentionally points out that, although extraterrestrial beings were very advanced in science and technology, there were many disadvantages. The significant concern of the author is mechanical-oriented living without spiritual value, which, she thinks, does not constitute real happiness. The author compares such a condition to the low-tech but peaceful life of a contented Thai countryman.

The theme the author clearly supports is that feelings, including love and care, are more valuable than a convenient life provided by science and technology. Although people in remote areas know only local cultural rituals for solving problems, their hearts are warm with love and care from kinship, which is absent among the extraterrestrial beings. It is true that the effectiveness of any kind of supernatural power has never been proven scientifically; however, its power to console and comfort the mind is almost always preferable to cold scientific certainty.

In contemporary Thai novels and also in the real world, even persons who are educated and apparently disbelieve in the supernatural sometimes 'do as the Romans $d o$ ' when they encounter cases that are 
performed according to superstitious beliefs. Some examples are performing the ritual of permission-request from guarding spirits before starting any activity. Holywater bathing to dispel bad luck is also regularly practiced among Thai people. With this kind of superstitious application, it is hard to define the practitioners's real attitudes toward the supernatural. However, it does show the influence of supernatural ideas that permeate every social class in Thailand.

The second dominant factor in Thai society is Buddhism, which is the major religion of Thai people. For a clear understanding of the Thai style of Buddhism, which is the most influential source that governs Thai thoughts, the following explanation by Phya Anuman Rajadhon (1972: 192), a highly esteemed Thai scholar, shows a fine background.

Animism, with ancestor-worship, is the primitive belief of the Thai $[\ldots]$ this formed the first layer of Thai religion. Later on came Buddhism and the Thai adopted it as their national religion. [...] the Thai inherited a fair proportion of Hinduism through the influence of the Cambodians [...] Whatever cults and beliefs are adopted by the Thai, they are readily modified to suit their temperament and surroundings. When they adopted Buddhism, they modified their basic belief of animism into the fold of Buddhism. Likewise when they embraced Hinduism, they adapted it as a subordinate to the former. As Buddhism and Hinduism were evolved from one and the same source, i.e.

\begin{abstract}
Brahminism, there was no hindrance to their assimilation. They became in time intermixed completely, and of course tinged with the former animistic belief. ${ }^{2}$
\end{abstract}

The long history of Buddhism in Thailand makes it quite difficult to gauge its true value in the conception of general Thais. Instead of teaching and practicing the scientific form of Buddhism, most Thais favor and expect miracle from their religion. This distortion and misguided value are clearly reflected in many of the studied novels. The close structure of two novels, The Oracle (Phutesaun, 1991) and Illusions (Tomayanty, 1995) are good examples of this point.

These two stories center around the reasonable scientific teachings of Buddhism; however, the authors' imaginings about Hindu gods were confusingly mixed with their main thoughts. The stories, consequently, portray more supernatural or superstitious angles of Buddhism than scientific characteristics. Regardless of whether it is intentional or unintentional, the reflection is another piece of evidence for the influence of supernatural thought in Thai society.

The images of Buddhism, represented by Buddhist temples and monks shown in most of the novels studies as places and persons provide consolation to the sufferers. When encountering bad fortune, Thai people prefer to find solutions from their acquaintances or famous monks. The suggestions which are usually given include giving alms, meditating, wearing amulets or

\footnotetext{
${ }^{2}$ This translation is from "The cultures of Thailand", available at www.mahidol.ac.th/Thailand/glance
} 
sacred materials, and so on. These practices are accepted and performed by both the middle and the lower classes, who tend to believe in the supernatural more than the highly educated upper class.

Normally, religion plays less of a role among the elite than among the general populace. Formal education is a significant factor in weakening people's beliefs in religion and in the supernatural in general. Many contemporary authors insist through their protagonists that education, a degree from a university, refuses the existence of any supernatural power, as for example, in The Lapse Worlds (Arita, 1990: 321) and The Oracle (Phutesaun, 1991: 60). On the contrary, local people, both in real-world society and in fiction, whose culture and religion are closely related to certain aspects of the supernatural, plainly regard such non- empirical forces as normal components of life.

\section{Science and technology: The formally accepted ideas of sophisticated Thais}

Most of the novels studied present stories of sophisticated metropolitan people. Nearly all the protagonists have higher education. Most are Ph.D. graduates, or at least hold a degree, in the field of science in particular. Seventy percent of the protagonists, representing modern sciences, maintain and advocate scientific ideas. Thirty-five percent of the antagonists opposed science and technology that might cause disasters. Eleven novels $(55 \%)$ presented the antagonists as agents or performers of negative supernatural forces (black magic). Only five stories $(25 \%)$ demonstrated the protagonists accepting the existence and usefulness of both scientific, technological ideas and supernatural forces.
From the above figures, it can be concluded that contemporary Thai authors support the current idea that science and technology are agreeable and beneficial to the present world. However, a smaller percentage $(25 \%)$ of the studied novels shows some concerns about risks that science and technology may bring along with progress. A remark that should not be overlooked here is that science and technology are formally accepted ideas only among sophisticated Thais, few in proportion and resident only in metropolitan areas. Therefore, an interesting question to be examined is whether scientific thought depends on social, economic, and cultural environment. Can it flourish in remote areas among less-educated people?

A few of the novels studied reflect some insight on education in Thai society. Two authors (Kukrit, 1988, and Weerawat, 1994) even criticize some educated people for not applying knowledge to their lives but being dominated by surrounding practices, such as consulting fortune-tellers when encountering problems or choosing to be silent when their scientific reasoning was not accepted.

Even some scientists presented in some novels studied plainly accept ideas about the supernatural. A novel entitled The Mystic Island (Navy, 2002) is a clear example. The main story presents a botanist's endeavors to conserve a rare wild flower on a mystic island. The scientist knows the story of the flower and the location of the island from a local old man who claims to have the powers of telepathy and clairvoyance. The protagonist believes the story of the informant without any objection and also supports the idea that such abilities wade use of psychological science that was more advanced than the physical one. 
Claims that extra sensory perception (ESP) is a kind of psychological science are often found and repeated in contemporary Thai novels. The authors always support the idea with information from western media reporting about studies or news of these phenomena. Accordingly, it seems hard to draw a line between science and the supernatural. Not only are people in rural areas fascinated by supernatural power, the metropolitan sophisticates, both Thais and Westerners alike, are also lured to find evidential support for this mystery.

In two successful Thai science fiction novels written for teenager readers, The White Road (Dr. Pop, 2003) and Beyond the Horizon (Jutarat, 2002), modernistic, technological future worlds are presented in which the supernatural is developed as a branch of advanced science and plays an important role along with other fields of science and technology. From this perspective of young contemporary writers, the supernatural does not seem meaningless or rightfully overlooked. Although the themes of the two novels are influenced by Hollywood blockbuster films, they also seem like an agreeable trend of the present globalized era.

Among the agreeable ideas of science and technology for the modern world, the young author of The Fantastic Forest (Sirikarn, 2003) presents deep concerns about a future world totally designed and controlled by scientists. This is a classic theme of science fiction, disaster from an unexpected malfunction of science or technology. The author portrays the legendary problem that a genius scientist without ethics could bring about catastrophe. This concern, one of the main weak points of science, has never disappeared from people's minds.
The parallel presentation of scientific thoughts or procedures and beliefs in the existence of the supernatural are similarly found in many novels studied; for example, Under the Egyptian Shadow (Jintawee, 1992), The Black Magic (Sophee, 1996) and The Royal Puppet (Yaowares, 2002). The three novels provide similar stories in which Western scientists are trying to study and prove the supernatural scientifically. On the one hand, as it may be analyzed, the authors apply generally accepted ideas of science to raise the off-stream, nonsense status of the supernatural. On the other hand, it shows the authority of scientific thought that formally governs ideas of literate Thais, both writers and readers.

At any rate, both urban and rural Thais shared an interest in the supernatural. However, their purposes are different according to each own way of living. People in big cities, educated and individualistic, do some supernatural practices for working benefits or acquiring more scientific knowledge. They have no real belief or faithfulness in these noncorporeal phenomena. On the contrary, the rural people apply supernatural power to solve problems in their daily lives. Moreover, in many occasions these spiritual beliefs provide them luck or hopes as they wish.

In real society, there are many factors that serve to dissuade Thai people from thinking scientifically, especially those in areas of insufficient science or technology. Not only material factors, communication and transportation facilities or public health services, for example, obstruct the enhancement of scientific and technological concepts among Thais, local cultures which form the basic conceptions and worldview of the people, as stated previously, have 
also played prominent roles in inhibiting the creation of scientific minds. Yet, for science and technology advocates, this is not an insurmountable obstacle. There simply remain many aspects which need to be thought out and implemented.

\section{Roles and functions of the supernatural in Thai society}

The very point that most of the studied novels criticize about the supernatural is sorcery, which is the use of magic with the intent of harming rivals or enemies. Actually from the anthropological perspective, "magic may be used to benefit the community or an individual, or it may serve antisocial purposes" (Nanda, 1994: 361). Yet, many novels studied present the overall idea that the magic of sorcerers is evil and sinful and decent individuals should not engage in it. Another interesting reflection appearing in some novels is that this world is mechanical. All systems are planned and orderly processed. Thus, no one can break the rules, such as being immortal or controlling supernatural powers according to his or her wishes.

The two stated ideas are from the educated urban authors, who believe in empirical rationality. In the actual lives of rural Thais, as roughly appeared in few novels, many supernatural practices constitute their local knowledge for problem solving, which they can practically acquire with minimal expense; while modern science or technology are alien, belonging to specialists, expensive, and difficult to apply. One novel studied, The Double Worlds (Tomayanty, 1991), clearly describes how each world and era has its own, proper knowledge and technology. Civilization could not be measured by the alien standard. This strong view indirectly confirms that the usefulness or value of any knowledge is up to its context, time, and place.

It is interesting to examine the representation of the supernatural as a forbidden science that is unable to defeat the mechanical natural law of the world. From a cultural anthropological perspective, it has been long explained that this kind of idea was a measure of social control. It is observed, in the novels studied, that one purpose of using supernatural power is to break some rules or laws in order to gain special status or privilege for the practitioners. Therefore, to sustain the normally peaceful proceedings of society, some taboos or teachings are set to prevent any exceptional opportunities.

However, it is inevitable that social disorder exists in every society. The very simple cause is an individual's desires, envy, fear, hatred, and also love, that cause distortion and injustice among people. In the novels studied, the causes of using supernatural power most commonly found are for gaining supreme status or immortality, for defeating black magic, for defending against unknown harms, and for avenging oneself. All conflicts can be concluded according to the general rule that 'good deeds beat all evils'.

One widely criticized characteristic of Thai people is thinking illogically, expecting irrational things. One novel studied, The Fortune-Teller (Kaewkao, 1989), seriously discusses a favorite issue of Thai people, fortune-telling. The author presents the topic as if it had been a science since ancient times. She points out that capable fortune-tellers had to be versed in mathematics to perform advanced calculations, alert, comprehended sociological factors, and must behave morally. Many attitudes toward fortune- 
telling among Thai people, from lower to upper classes, are reflected, and its role has been accepted as serving the rich in stock investment, while the poor just hope for a little luck in winning the lottery.

The author also points out that supernatural power or sacred materials are especially needed or believed in by evil- doers who always do bad things. She explains that these kinds of people do not believe in religious teachings. In order to seek mental solace they, then, turn to the supernatural. The novel concludes that fortune-telling might help people to face their coming future with mental or physical preparation. However, the author insists that success depends not on ones' fortune but on ones good deeds. By the reasonable style of narrating the story, the author can raise awareness among readers of another aspect of some supernatural practices in Thai society which is useful and plays important role.

The endeavors of contemporary Thai novelists to present the supernatural scientifically are found in many angles which seem to be interesting and these points should be considered seriously. In The Sin Claimants (Tha-nawadee, 2000), author links the psychiatrist's science of hypnotism to the remembrance of past lives and the Buddhist teachings about the law of action and expiation. The story presents a young psychiatrist who believed in modern science and thought that the supernatural, whether related to Buddhism or not, was nonsense, while his father, a former physician who turned to practice, and had faith in, meditation, insisted that the supernatural, though non-empirical, really existed. From this story, it is seen that the supernatural is used as an example or a lesson to support the teachings of
Buddhism, the circle of life, and the law of action and punishment.

For modern Thai fantasy and science fiction, the presentation of the supernatural is adapted to be more fanciful and properly suits the high technological world than general realistic novels. In the future world, the novelist imagines the supernatural to be a special power for immediate healing and battling evil forces, as in The White Road (Dr. Pop, 2003). Though the views seem to be fashionable, they are not different from the present role of the supernatural in the belief of Thai people. Accordingly, it may be concluded that the supernatural really has a deep root and role in the Thai way of life. As far as it is necessary and useful, the supernatural will always exist, in fiction or in actual Thai society.

As stated above, although the majority of contemporary Thai novelists have focused on the negative aspect of the supernatural, some of its actual roles and functions in Thai society, especially in rural areas, are not neglected. It is portrayed in plural dimensions, both advantageous and disadvantageous. These provide good information for policymakers to change or limit this out-of-date view in Thai modern society. The considerations for further implementation may start with the following: If the scientific thought can substitute the present roles and functions of the supernatural, then it will not be in use any longer. If Thai living, especially concerning the government administration, fully operates on reasonable principles, then the supernatural will have no place in the Thai way of life. The concluding question is whether we can set these desired conditions or not. 


\section{Expectations of Thai novelists toward science, technology and the supernatural}

\begin{abstract}
Although contemporary Thai authors generally show clear attitudes favoring scientific and technological thought in their novels, readers can not sense any real faith in them. On the contrary, their stories, sometimes presenting lots of facts and figures about science and technology, do not demonstrate how significant science and technology are to individual life. Science and technology seem foreign and technical to most Thais. In order to make stories look reasonable and believable, most authors prefer to give references of foreign persons or documents, either fake or actual. Not only the advanced trends of science and technology but also the general principles as regarded by the Thai people are more valuable than their local knowledge. This kind of perception is a remarkable point that policymakers should not overlook.
\end{abstract}

For the supernatural, the contemporary Thai novelists also do not express real protest. Though they all denigrate the supernatural as irrational and unreliable, the authors, in many occasions, present the power of Buddhist rites as being able to prevent or destroy some black magic in a manner that looks exactly like supernatural power itself. To compare the faith in Buddhist teachings and its consequent miracles to the scientific and technological ideas, Thai authors favor the former much more than the latter. This feature works together with the above mentioned to obstruct advancement of science and technology in Thai society.

However, some novels studied show promise for science and technology advocates. In Beyond the Horizon (Jutarat, 2002), the author emphasizes viewing everything from many angles. She raises some examples of a man who is a bad husband but a good father at the same time, or what is understood as spirit might be scientifically explained by a law of physics as a form of energy. In this novel, the author presents a very good basic principle of science that directly affects our daily lives.

In The Invisible Form (Weerawat, 1994), the author criticizes Thai-style education for being a failure when compared with international pedagogical style. He observes that a Thai teacher, even a college graduate, is still fond of consulting fortune-tellers before doing anything. He also questions how we can expect children to think scientifically or critically when teachers themselves do not. The author, thus, clearly points out the problem using examples from actual Thai society.

In addition, this research has found many interesting aspects of science and technology from the literary perspective. In The Garuda (A.Arun, 2002), the author makes a strong remark on the relations between surprising ancient civilizations, such as Egyptian constructions the pyramids and advanced know-how, for example- with the Asian legend of Nagas and Garudas. He creatively plots a story that links a legend of conflicts of Nagas and Garudas to the possibility of visits to the earth by extraterrestrial beings who left behind some of their own civilization. Through imaginative story telling, a new scientific thinking and reasoning is presented, an inspiring role of science fiction which has, for a long time, been generated numerous actual scientific theories and inventions.

Another interesting novel that should also be mentioned is The Fantastic Forest (Sirikarn, 2003). The author warns the scientists that, although science and 
technology have provided many facilities, invented or applied from the nature, to human beings, we still have no right to disturb natural lives, either animals or plants. She points out that it would be worthless if, in order to prolong the human life, the whole of nature had to be changed or modified to serve this only purpose. It is concluded in the novel that if science and technology were controlled by human beings, namely the scientists, there would be a risk of malfunction, since human beings, who are controlled by their desires, are always unjust and imperfect; even scientific machines sometimes cause errors. The author hopes that human beings live harmoniously with nature. Although this remark is not new, it is necessary for it to be repeated and remembered. The author of The Fantastic Forest has interestingly done her duty.

Subsequently, let us consider knowledge in Thai society. Thai local knowledge seems to be derived mostly from observation of nature and usually aims at peaceful living. The major proportion of Thai people is living in harmony with nature, not controlling or defeating it as science, in some aspects, endeavors to do. Beside nature, another central source of knowledge and practices in Thai society is Buddhism. The novels studied clearly reflect this point. Generally it is accepted that Buddhism is a scientific religion. Its major teachings and practices are empirical and rational. Unfortunately most Thais understand only its outer layer of rites with the hope for its miracle.

Thus, according to many stated ideas in contemporary Thai novels, it may be concluded that although there are some blurred thoughts of science and the supernatural, many novels have reflected accurate and meaningful scientific views for consideration by those who wish to instill scientific thinking and technological knowledge in Thai society.

\section{Observation of Thai epistemic culture from a literary perspective}

Since the topic of this research focuses on science, which is a form of knowledge, the extended observation of the Thai culture of knowledge in these contemporary novels should be useful for compiling information on Thai epistemic cultures. The outline of the observation covers four topics, namely sources of knowledge, images of knowledge, concepts about knowledge, and contexts of knowledge. Some distinguishing points are found as follows.

There are three main sources of knowledge. Firstly, educational institutions: schools, colleges, and universities. These places provide formal education, mostly for office professions rather than agricultural work, which is the field of the majority Thais. A few novels state that this formal education does not suit the lives of countryfolk who have to work on farms. Labor, even from children, is needed, and work for daily life is more important than going to school. The knowledge deemed important by local people concerns farming, which they can learn in the field and by practicing, not in classes or by reading or writing. Therefore the most basic principles of science are missed out on by most of local Thais.

The second and third sources of knowledge for Thai people are socialization and Buddhism, which, on the contrary, embody major, practical knowledge that can be acquired from parents and family members in one's own home. These two types of knowledge, religion and rules for living in 
communities, are enough for a peaceful Thai lifestyles, especially in rural areas, while formal education seems worthwhile and necessary for urban people, since it is a means for building their careers and reputations, as their style of living is different from that of the people in remote areas. Accordingly, a primary remark that can be concluded here is that importance of education, for Thais, either rural or urban, is assessed by its utility in living harmoniously with the environment. "If science and technology have to find places in rural communities, they should be adjusted to suit their target groups." (Soraj, 2002: 257).

Next, the images of or attitudes toward knowledge, according to the results obtained from this study, may be grouped into three classes. Firstly, with respect to science and technology, most novelists present them as sophisticated knowledge for the metropolitan upper class, in particular. It may seem surprising that science and technology have never been viewed as simple, familiar, and being a part of daily life. Secondly, the supernatural has, on the contrary, been placed in a close and handy position in Thai minds. This special status has been mainly introduced through the process of socialization, and slightly supported by the insufficient administration from the central government. The supernatural, therefore, has performed many roles instead of formal scientific procedures. The third factor is Buddhism, which can be assumed to be the heart of most of Thais. This becomes apparent when Thais encounter trouble, as they will usually find solutions in their religious teachings. Thus, for Thais, Buddhism constitutes the whole source of knowledge, be it mental or practical.
Regarding Thai conceptions of knowledge, four interesting topics are found. Firstly, Thai people are aware that modern education or knowledge is one criterion used to divide people into classes. Higher education brings better career opportunities and aids in other forms of progress, which means a brighter and more promising future. Also, the patriarchal system of Thai society mandates that men should receive better education than women in order to play a major role in the family, an example of which is reflected in The Fortune-teller (Kaewkao, 1989: 7).

Consequently, as the studied data are mainly centered around two areas of knowledge, that is the modern one consisting of science and technology and the rather outdated one consisting of belief in the supernatural, this second concept is found: there are two aspects of knowledge, good and evil. Certainly, the supernatural is depicted as evil, while religious teachings are considered to be a good force. In many novels, black magic is finally defeated by the goodness of religious power. This concept is related to the taboos of the supernatural for social control purposes. Science and technology are viewed neutrally, as either good or evil, depending on who controls them.

The third concept is that Buddhism is the whole source of knowledge, because it covers all knowledge for leading one's life. Regardless of whether they are dealing with physical or mental problems, Thai Buddhists believe that everything can be solved by their religious teachings. The fourth concept of knowledge found in the study is that supernatural power is the last source of hope. This concept simply shows the human nature of mankind, that, when fulfillment is needed, every chance is taken, 
and the supernatural is usually the last resort.

The last topic is context of knowledge in Thai society. The findings well support the topics already described. When dealing with education, the taught subjects and the teaching processes are criticized for not being suitable for rural life. For science and technology, even scientifically-oriented people sometimes follow superstitious practices in order to avoid conflicts or not to be alienated. It could be summarized that, in Thai society, belief in the supernatural has deep roots and play a dominant role in the lives of Thai people.

\section{Some solutions}

Corresponding to the starting questions of this paper and the sequentially described details, as the researcher on this project, I would like to propose these conclusions as some preliminary answers.

It is clear that local cultures are more influential on Thai living than modern science, which Thai people consider occupational knowledge rather than practical concepts for solving problems or acquiring knowledge in their daily lives. This directly indicates that science education in Thai society is inefficient and has failed to achieve its primary goals. Thai people, both in urban and, especially, in rural areas, are not effectively trained to form scientific minds sets and to apply it as apparatus for improving their lives. The problem of sufficient and well-trained teachers of science has long been discussed and the situation in Thai society is steadily improving. However, only this point will not solve the whole issue. Generally, most science education is delivered to Thai people only through formal education. For the public, there are few chances of gaining an adequate knowledge of science.
For publicizing knowledge of science or creating a scientific culture, Godin and Gingras (2000: 47) propose three forms of public understanding of science. Firstly, formal education focuses on the teaching and learning of science and technology in educational institutions as well as informal education. Both channels are geared to acquaint the whole of society with living in a scientific and technological environment. Secondly, mass media communication raises awareness and application of knowledge of science and technology for the public. And thirdly, social and organizational management form and develop any units or communities to work mainly on scientific and technological activities and to monitor and investigate related concerns.

In Thai society, education of science and technology has centered only around formal education and has overlooked the informal form for the general public. This implementation is very limited for both being the initial force and the final outcome of creating a science-and-technologyliterate society. Another influential factor that seems to be keeping Thai society science illiterate, as has been discussed, is Buddhism, which is at present distortedly perceived. The scientific characteristics of Buddhist teachings are not being correctly taught, while outer layers of the religion, such as miracles and sacred materials, are widely disseminated instead.

In the old days, Buddhism was the main source of education in Thai society. Both religious content and practice were directly delivered to learners by respected monks. In contrast, nowadays formal education by teachers who have graduated with any degree, teach only stories, histories, and teachings of the religion, hardly focusing on Buddhist scientific principles of thought or 
knowledge or the Buddhist way of life. Dhammapitaka (Payutto, 2001: 27) has pointed out that "the present mission of Thai education is narrowly limited, compared to the past. Modern educators set knowledge to cover only information or content and know-how for professions. The real meaning of education which is developing human beings is simply ignored."

However, the latest education reform in 1999 showed a good sign from involved parties of restructuring Thai education to be a more effective and powerful function in society. The problems of mistaken perceptions of science and Buddhism, as discussed, may be solved by the same procedure, that is, effective education. Focusing on education of science and technology, the right mission, developing human beings, must be established and a multidimensional approach must be implemented widely and continuously among the public.

As most of the novels studied reflected, educated Thais well understand the benefits of science and technology in this modern world. They clearly view how out-of-date beliefs in the supernatural are and are fully aware that its usefulness is only for mental consolation. To encourage scientific thoughts or technological knowledge among Thai people, there is no need to diminish the role of local cultures or Buddhism. Instead, procedures will be very effective if policymakers can design encouragement that compromises between these two dominant factors.

Many anthropologists all over the world have studied and agreed that cultures, including beliefs and practices regarding the supernatural and religions, are important and necessary for surviving in all societies.
Roles and functions of these two factors are widely effective and beneficial to members of the society. Although, nowadays science and technology are the new competitors, they can never be substitutions. The variability is, for now and in the far future, the beauty of nature and the world.

\section{References}

A. Arun. 2002. The garuda. Bangkok: Double-Nine Printing. [in Thai] Anuman Rajadhon. 1972. Culture. Bangkok: Bunnakarn Press. [in Thai]

Arita. 1990. The lapse worlds. Bangkok: Chokchai-dhewest Press. [in Thai]

Baldwin, E., et al. 2004. Introducing cultural studies. Revised $1^{\text {st }}$ ed. Essex: Pearson Education.

Cetina, K. K. 1999. Epistemic cultures: How the sciences make knowledge. London: Harvard University Press.

Dhammapitaka. 2001. Where is Buddhism in eduation reform? $2^{\text {nd }}$ ed. Bangkok: Sahadhammic Press. [in Thai]

Dr. Pop. 2003. The white road. Part 1 No.1. $4^{\text {th }}$ ed. Bangkok: Siam-inter Books. [in Thai] 2003. The white road. Part 1 No.2. $5^{\text {th }}$ ed. Bangkok: Siam-inter Books. [in Thai] 2003. The white road. Part 1 No.3. Bangkok: Siam-inter Books. [in Thai]

During, S. 2005. Cultural studies: A critical Introduction. London: Routledge.

Godin, Benoit and Yves Gingras. 2000. 
Public understanding of science, Vol.9, No.1, 43-58. SAGE

Publications.

Harris, M. 1979. Cultural materialism:

The struggle for a science of culture. New York: Random House.

Jintawee W. 1995. Under the Egyptian shadow. $2^{\text {nd }}$ ed. Bangkok: Reumsarn Press. [in Thai] 1976. The immortal desire. Bangkok: Reumsarn Press. [in Thai]

Jutarat. 2002. Beyond the horizon. $6^{\text {th }}$ ed. Bangkok: Perndee Press. [in Thai]

Kaewkao. 1989. The fortune-teller. Bangkok: Reumsarn Press. [in Thai] 1985. Mantra. Bangkok: Reumsarn Press. [in Thai]

Kesra Bun. 2003. The devil shrine. $2^{\text {nd }}$ ed. Bangkok: Double-Nine Printing. [in Thai]

Kukrit P. 1989. The Bangpleng blackbird. Bangkok: Siam-rat Press. [in Thai]

Nanda, S. 1994. Cultural anthropology. California: Wadsworth Publishing.

Nantana W. 1987. The Extraterrestrial. Bangkok: Chokchai-dhewest Press. [in Thai]

Navy R. 2002. The mystic island. Bangkok: Double-Nine Printing. [in Thai]

Ngampis S. 2000. Cultural anthropology. $4^{\text {th }}$ ed. Bangkok: Rama Press. [in Thai]

Nidhi E. 2002. Before the Ariya era: On religion, beliefs, and moral. Bangkok: Mathichon Publishers. [in Thai]

-------. 2000. Buddhism in the changing society. Bangkok:

Komolkeemtong
Foundation Press. [in Thai] 2003. Hitech-miracle: On science and technology in Thai society. Bangkok: Mathichon Publishers. [in Thai]

Phutesaun. 1991. The oracle. Bangkok: Reumsarn Press. [in Thai]

Roberts, A. 2000. Science fiction. London: Routledge.

Sirikarn. 2003. The fantastic forest. Bangkok: Fantasia Press. [in Thai]

Sophee P. 1996. The black magic. $2^{\text {nd }}$ ed. Bangkok: Reumsarn Press. [in Thai]

Soraj H. 2002. Science in Thai society and culture. Bangkok: Institute of Academic Development (IAD) Press. [in Thai]

Supatra S. 1977. Thai society and culture. $2^{\text {nd }}$ ed. Bangkok: Thaiwatanaphanit Press. [in Thai]

Tha-nawadee. 2000. The sin claimants. $3^{\text {rd }}$ ed. Bangkok: Double-Nine Printing. [in Thai]

Tomayanty. 1991. The Double worlds. $5^{\text {th }}$ ed. Bangkok: Bamrungsarn Press. [in Thai] 1995. Illusion. $2^{\text {nd }}$ ed. Bangkok: Na-banwanakram Press. [in Thai]

Weerawat K. 1994. The invisible form. $2^{\text {nd }}$ ed. Bangkok: Nabanwanakram Press. [in Thai]

Williams, R. 1967. Culture and society $1780-1950.4^{\text {th }}$ ed. London: Chatto \& Windus.

Yaowares D. 2002. The royal puppet. $2^{\text {nd }}$ ed. Bangkok: Double-Nine Printing. 